\title{
Investigating the Relationship between Responsibility-Taking and Identity Crisis among One-Child Students
}

\author{
Ebrahim Namani1 ${ }^{*}$, Samaneh Firouzian ${ }^{2}$, Faezeh Pardakhti ${ }^{2}$ \\ ${ }^{1}$ Department of Educational Sciences, Faculty of Literature and Humanities, Hakim Sabzevari University, Sabzevar, Iran \\ ${ }^{2}$ Department of Psychology, Faculty of Humanities, Islamic Azad University, Neyshabur Branch, Neyshabur, Iran \\ Email: *hakim@hsu.ac.ir
}

How to cite this paper: Namani, E., Firouzian, S. and Pardakhti, F. (2018) Investigating the Relationship between Responsibility-Taking and Identity Crisis among One-Child Students. Open Journal of Psychiatry, 8, 61-72.

https://doi.org/10.4236/ojpsych.2018.81005

Received: December 26, 2016

Accepted: January 2, 2018

Published: January 5, 2018

Copyright (c) 2018 by authors and Scientific Research Publishing Inc.

This work is licensed under the Creative

Commons Attribution International

License (CC BY 4.0).

http://creativecommons.org/licenses/by/4.0/

cC) (i) Open Access

\begin{abstract}
The present study has investigated the relationship between responsibility-taking and identity crisis among one-child students. This research is a descriptive-correlational study and the target population comprised all one-child female students of Mashhad secondary schools in the academic year 2014-2015. In this study, multistage cluster sampling method was applied and finally, Region 4, 6 and 7 were randomly selected and 150 students were also randomly chosen according to Morgan table. The research data was collected through California Psychological Inventory (CPI) and Ahmadi identity crisis questionnaire. The obtained information was analyzed by Pearson correlation test and regression. The achieved results indicated that the relationship between responsibility-taking and identity crisis among students is statistically reverse and significant at the level of $\mathrm{p}<0.01$. In other words, with reducing the identity crisis in students, their responsibility-taking increases. As a result, the main research hypothesis indicating the relationship between responsibility-taking and identity crisis among one-child students of Mashhad secondary schools was confirmed.
\end{abstract}

\section{Keywords}

Responsibility-Taking, Identity Crisis, One-Child

\section{Introduction}

Today, more different trends than in the past are seen in society regarding the family structure and it seems that great changes are taking place from what we know as a traditional family to modern family. One of these major changes has been a decrease in the household population in the past decades which can lead 
to an increase in the number of one-child families [1]. Accordingly, child birth or so-called fertility in our country has undergone significant changes during the last three decades. Changes in lifestyle, rising costs and economic problems, education and employment of women, application of population policies and marriage at older ages have led to a significant reduction in fertility rate in the country and this means that today, most Iranian families tend to have only one child. Increasing one-child families and its consequences have caused many family experts, psychologists and sociologists to further consider this issue [2] [3] [4].

Many families believe that if they have only one child and are able to provide him/her with the required teachings and facilities at different stages of life in the best way, they will have a safe life and this removes all of their doubts about the birth of several children which perhaps for different reasons, they are not able to guarantee a bright future for them [3]

One of the important stages of the child's life is the period of adolescence. Adolescence is a period of transition from childhood to adulthood; a period which most growth theorists believe that starts from about eleven years of age and continues until the end of the maturity period, i.e. when the adolescent is awarded the full advantages of adulthood [4]

"Adolescence is a period of important changes in the academic and social life of an individual. The importance and sensitivity of this period is in such a way that in the discussion of inner secrets, Rousseau calls growth, puberty and adolescence as second birth" [5].

An important issue faced by parents, especially one-child parents, in the first stages of their child's adolescence is the problem of identity. Identity is a response to whatness and whoness of each person and in fact is a set of characteristics that distinguishes a person from others. Hence, no human being can continue his social life without having an identity. The word identity in Persian has been originally taken from a word which means "he". Thus, the identity of each phenomenon represents its existential nature and identity crisis is the damage to this existential totality [6].

An adolescent is in search of individuality and autonomy and creating an independent identity for himself. He considers himself as a developed individual who has the ability to make decisions about his personal matters but lives in a world which is controlled by adults [7].

A variety of factors is effective in an adolescent's identity formation including family, school, religious-social institutions, mass media and peers. Nevertheless, since family is the first institution that forms the basic foundations of the adolescent's personality from childhood, it is of crucial importance [8].

If the personal identity of an adolescent is shaped over time and based on the experiences resulting from correct social attitude and the youth recognizes himself and separates himself from others, his mental balance is ensured; but if he suffers from role ambiguity instead of having self-awareness and forming a posi- 
tive identity, his mental balance and coordination are disturbed and he becomes entangled in identity crisis. Thus, growth and development of the youth depends on this crisis. A well-formed and integrated identity structure gives a sense of purposefulness and having direction to the individual and ultimately helps him in decision-making, problem-solving, effectively coping with the requirements of daily life and adapting to new environments [9].

Erikson regards identity crisis as normal but considers the inability to cope with it as abnormal since it deprives the individual of a strong identity and if not resolved successfully, is followed by role confusion, running away from home, delinquency and serious psychiatric illnesses [10].

One of the basic skills whose achievement is of great importance in the formation and dynamics of a proper identity in adolescents and especially one-child individuals is responsibility-taking which alone refers to a sense of dutifulness, accountability and obligation [11].

Responsibility-taking is deemed as one of the basic and necessary skills for each person. Responsibility-taking means acceptability, responsiveness and undertaking a job requested from someone and the individual has the right to accept or reject it. Responsibility-taking is created in the process of proper human development [12]. It is a matter that ensures to a great extent the performance of useful jobs and prevention of harmful works [13].

Future requires responsible people with more ability to choose; people who are able to make plans based on their own needs not on the basis of others' planning for them [14].

Glasser believes that the individuals who have a confused identity show states such as weakness, irresponsibility and lack of confidence. He argues that people should be responsible in order to enjoy better feelings about life.

Fostering the sense of responsibility-taking of the child in adolescence is possible through assigning him some duties that were previously assumed by parents [15].

It is through the family that the adolescent learns how to communicate with others, put order and discipline in affairs in priority, have compatibility and assume the responsibility of his own actions. Parents' behavior towards adolescents is very important and effective in their responsibility-taking [16].

After family, we can mention other social institutions such as school, university, military centers (for boys) and work environment (including governmental and non-governmental organizations and departments) as other factors affecting the formation or strengthening of the responsibility-taking skill as an important social skill in one's life. From this perspective, addressing the issue of responsibility- taking as a social skill and also as one of the most important aspects of adolescents' identity development has been considered by many scientists and researchers in various fields, especially psychology and counseling.

[17] in their study have assumed responsibility-taking as an intermediary of important variables such as the quality of doing assignments and a sense of selfefficacy for academic success. The research results have also strongly confirmed 
this hypothesis. The results have shown that successful students are those who give more importance to their assignments and regard themselves as more responsible for their academic performance than teachers and educational system.

In another study, [18] examined the relationship between self-esteem, autonomy and justice with responsibility-taking of female students in Varamin Middle Schools. The results demonstrated that the variables of perceived autonomy, selfesteem, self-concept, warm and fair relationship between school authorities and accepting the active role of students in school directly or indirectly have had a significant impact on their responsibility-taking.

[19] conducted a study on elementary and middle school students with the aim of investigating the role of classroom discipline in strengthening the responsibility-taking of students in order to protect the rights of learners in the classroom. Based on the findings, use of repressive techniques against students' behavior inhibits the growth of their responsibility-taking and diverts their attention from school assignments. He obtained other results from this study including that the students interested in learning have more responsibility-taking and boys are less responsible than girls. [20] demonstrated in their study that those with more responsibility further enjoy their sports activities.

After performing a study on male and female students aged between 15 and 18, [21] came to the conclusion that compared to male students, issues such as communication with others and responsibility-taking are the main dynamics in the definition of identity for female students.

[22] conducted a research and analyzed the relationship between identity styles with general health and responsibility-taking in students of Tehran University. The results revealed that there is a positive relationship between informational and normative identity styles with responsibility-taking but a negative relationship between confused identity style and responsibility-taking.

With regard to the mentioned points and identifying the significant role of responsibility-taking skill in different aspects of individuals' personality which altogether result in the formation of their identity and also expansion of the interest in having only one child in the Iranian society and concern of many parents with one child about proper identity formation in their children, it seems necessary to deal with the issue of responsibility-taking in one-child individuals and examine the relationship between responsibility-taking and identity crisis and also the amount of this relationship in one-child students. Therefore, in the present study, the following research propositions have been sought:

1) There is a relationship between responsibility-taking and identity crisis in one-child female students (main hypothesis).

2) Identity crisis is a predictor of responsibility-taking of one-child female students (secondary hypothesis).

\section{Research Methodology}

The present study is a descriptive and correlational research in which the rela- 
tionship between responsibility-taking and identity crisis in one-child students has been investigated. In this study, the researcher evaluates the relationship between variables in order to investigate the type and amount of the intended relationship.

\section{Statistical Population and Sampling Method}

The target population in this study consists of all one-child female students in secondary schools of Mashhad in the academic year 2014-2015.

The statistical sample in question includes 150 one-child students in Mashhad who were selected based on Krejcie \& Morgan table.

To choose them, multistage cluster sampling method has been employed; that is, after receiving the list of one-child high school girl students studying in seven regions of Mashhad (in the academic year 2014-2015) from Education Department, initially three regions were randomly selected and then, 16 secondary schools were chosen from among the girl secondary schools of the selected regions and from each secondary school, one grade was randomly chosen and questionnaires were distributed among them.

It is important to mention that all the participants declare their consent to participate in this research.

\section{Research Tool}

In this research, the following tools have been used in order to examine the variables in question:

\section{1) Responsibility Scale of California Psychological Inventory (CPI)}

This scale includes 42 questions, which has been prepared with the aim of assessing the rate of responsibility-taking in normal individuals with 12 years of age and older and the respondents answer the questions in the form of "agree" and "disagree" [18].

[14] reported that the reliability coefficients of the California Psychological Inventory through test-retest method and internal consistency have been quite satisfactory relative to other personality questionnaires. After exploring numerous studies concerning the questionnaire, Gough concluded that the range of the coefficients of test-retest reliability and internal consistency of each is between the median of 0.52 and 0.81 and the median of the coefficients of its overall reliability is equal to 0.70 . Reliability coefficients of the questionnaire were calculated using Cronbach's alpha and split-half methods which are respectively 0.76 and 0.88 .

\section{2) Identity Crisis Questionnaire}

This test has been designed by Ahmadi in Isfahan University. The rate of adolescents' affliction by identity crisis is evaluated with an emphasis on 10 separate sections. In developing this questionnaire, different diagnostic aspects of the crisis have been classified as follows:

a) Drawback in long-term goals; b) Indecision in selecting the job; c) Lack of a 
suitable model for friendship; d) Inappropriate sexual behavior; e) Difficulty in religious knowledge and introduction; f) Lack of attention to moral values; g) Failure to comply with group commitment; h) Having a negative view of oneself; i) Lack of the spirit of effort and innovation; j) Disruption in timing.

A score of zero to 3 is assigned to each question. Score 0 indicates lack of identity problem and score 3 represents high levels of identity crisis in an individual. The maximum test score which shows the highest identity crisis is equal to 30 and minimum score of identity crisis is 9 and the scores lower than 9 suggest lack of identity crisis. For validation, Ahmadi presented this test after setting to the experts in Faculty of Educational Sciences of Isfahan University and Khorasgan Islamic Azad University and they confirmed its content validity. Afterwards, the test was implemented on 60 high school students in Isfahan. They confirmed the comprehensibility, clarity and face validity of the questions. Ahmadi obtained the reliability coefficient of 0.78 for this test through split-half method (odd and even). Again, the questionnaire was distributed among 30 students and the correlation coefficient of 0.89 was achieved. Then, the reliability coefficient of personal identity test was obtained to be 0.92 using Spearman- Brown reliability coefficient.

\section{Data Analysis Method}

Data obtained from the tests of this research was analyzed using indicators of descriptive statistics (such as table, frequency, mean and standard deviation) and indicators of inferential statistics (such as Pearson correlation test and regression).

\section{Research Findings}

\section{1) Descriptive Findings}

In this section, the studied sample has been described using tables in terms of demographic characteristics with descriptive statistics (frequency, percentage, mean, standard deviation, maximum and minimum).

Table 1 shows the frequency and percentage of students in terms of school grade, age, field and educational region. As can be seen in the table below, most of the students under study are in the first year of high school and accordingly, students who have not still selected their field have the highest frequency (43.33) and after them, respectively fields of experimental sciences, humanities, mathematics and physics are next in rank. Moreover, Table 1 indicates that more than half of the students under investigation (56\%) are in the educational region 6.

Table 2 represents the descriptive indicators (mean, standard deviation, minimum and maximum) related to the studied variables of students. As can be observed in this table, the average score obtained from this test is greater than 21 and it can be concluded that the rate of students' responsibility-taking is slightly above average.

As to the identity crisis, given the manner of interpreting the test scores which 
Table 1. Frequency and percentage of students in terms of school grade, age, field and educational region.

\begin{tabular}{|c|c|c|c|c|c|c|c|c|c|c|c|c|c|}
\hline & \multicolumn{3}{|c|}{$\begin{array}{c}\text { School grade } \\
\text { (secondary school) }\end{array}$} & \multicolumn{3}{|c|}{ Age (in years) } & \multicolumn{4}{|c|}{ Field of study } & \multicolumn{3}{|c|}{ Educational region } \\
\hline & First & Second & Third & 15 & 16 & 17 & - & $\begin{array}{l}\text { Math and } \\
\text { physics }\end{array}$ & $\begin{array}{l}\text { Experimental } \\
\text { sciences }\end{array}$ & Humanities & 4 & 6 & 7 \\
\hline Frequency & 65 & 47 & 38 & 49 & 61 & 40 & 65 & 26 & 32 & 27 & 17 & 84 & 49 \\
\hline Percentage & $43.3 \%$ & $31.3 \%$ & $25.3 \%$ & $32.7 \%$ & $40.7 \%$ & $26.7 \%$ & $43.33 \%$ & $17.33 \%$ & $21.33 \%$ & $18.0 \%$ & $11.3 \%$ & $56 \%$ & $32.7 \%$ \\
\hline \multirow{2}{*}{ Total } & & 150 & & & 150 & & & & 150 & & & 150 & \\
\hline & & 100 & & & 100 & & & & 100 & & & 100 & \\
\hline
\end{tabular}

Table 2. Descriptive indicators related to the studied variables of students.

\begin{tabular}{cccccc}
\hline Variables & Frequency & Lowest score & Highest score & Mean & Standard deviation \\
\hline Responsibility-taking & 150 & 13 & 36 & 23.96 & 4.70 \\
Identity crisis & 150 & 0 & 53 & 13.62 & 4.83 \\
\hline
\end{tabular}

Table 3. Correlation matrix between responsibility-taking and identity crisis components of students.

\begin{tabular}{|c|c|c|c|c|c|c|c|c|c|c|c|c|c|}
\hline & Variables & 1 & 2 & 3 & 4 & 5 & 6 & 7 & 8 & 9 & 10 & 11 & 12 \\
\hline & Responsibility-taking & 1 & & & & & & & & & & & \\
\hline 2 & Drawback in long-term goals & -0.146 & 1 & & & & & & & & & & \\
\hline 3 & Indecision in selecting the job & $-0.196^{*}$ & $0.385^{* *}$ & 1 & & & & & & & & & \\
\hline 4 & Lack of a suitable model for friendship & -0.124 & 0.058 & $0.214^{\star *}$ & 1 & & & & & & & & \\
\hline 5 & Inappropriate sexual behavior & $-0.351^{\star *}$ & $0.194^{*}$ & 0.209 & 0.031 & 1 & & & & & & & \\
\hline 6 & $\begin{array}{l}\text { Difficulty in religious knowledge } \\
\text { and introduction }\end{array}$ & $-0.350^{* *}$ & 0.158 & 0.156 & 0.001 & 0.083 & 1 & & & & & & \\
\hline 7 & Lack of attention to moral values & $-0.216^{* *}$ & $0.174^{\star}$ & 0.176 & 0.022 & 0.094 & 0.149 & 1 & & & & & \\
\hline 8 & Failure to comply with group commitment & 0.022 & $0.226^{* *}$ & 0.138 & 0.118 & 0.070 & $0.177^{*}$ & 0.013 & 1 & & & & \\
\hline & Having a negative view of oneself & $-0.232^{\star *}$ & $0.286^{\star *}$ & $0.385^{\star *}$ & $0.229^{* *}$ & $0.324^{* *}$ & $0.169^{*}$ & $0.167^{\star}$ & $0.223^{\star *}$ & 1 & & & \\
\hline & Lack of the spirit of effort and innovation & $-0.283^{* *}$ & $0.342^{\star *}$ & $0.320^{* *}$ & $0.179^{*}$ & $0.187^{*}$ & $0.236^{* *}$ & 0.138 & $0.264^{\star *}$ & $0.474^{\star *}$ & 1 & & \\
\hline & Disruption in timing & $-0.177^{\star}$ & $0.234^{\star *}$ & $0.413^{* *}$ & $0.176^{*}$ & $0.214^{* *}$ & 0.063 & $0.304^{\star *}$ & 0.076 & $0.414^{\star *}$ & $0.359^{* *}$ & 1 & \\
\hline & Total score of identity crisis & $-0.385^{\star *}$ & $0.539^{* *}$ & $0.639^{* *}$ & $0.351^{* *}$ & $0.456^{* *}$ & $0.431^{* *}$ & $0.377^{\star *}$ & $0.447^{* *}$ & $0.719^{* *}$ & $0.674^{* *}$ & $0.639^{* *}$ & 1 \\
\hline
\end{tabular}

$\left.{ }^{*}\right)$ Significance at the level of $0.05 ;\left({ }^{*}\right)$ Significance at the level of 0.01 .

was mentioned before, the average of the obtained scores (13.62) and its proximity to zero suggest that students have high potential in identity-making.

\section{2) Data Analysis}

In this section, the information obtained from the study was analyzed using inferential statistical tests (Pearson correlation test and regression testing) in order to reply to the hypotheses.

Main Research Hypothesis: There is a relationship between responsibilitytaking and identity crisis in one-child female students.

Table 3 shows the correlation matrix between responsibility-taking and identity crisis components of students. To investigate the relationship, Pearson cor- 
relation test was used. The following table shows that the relationship between responsibility-taking and identity crisis components (indecision in selecting the job, inappropriate sexual behavior, difficulty in religious knowledge, lack of attention to moral values, having a negative view of oneself, lack of the spirit of effort and innovation, disruption in timing and total score of identity crisis) of students is statistically reverse and significant at the level of $\mathrm{R}<0.01$ and $\mathrm{R}<0.05$. In other words, with a reduction in the mentioned components, their responsibility-taking increases. As a result, the main research hypothesis stating that there is a relationship between responsibility-taking and identity crisis in one-child students of Mashhad secondary schools is confirmed.

Secondary Hypothesis: Identity crisis is a predictor of the responsibility-taking of one-child female students.

In order to test the secondary research hypothesis, regression testing was applied and the results have been provided in Tables 4-6.

Table 4 indicates that totally $15 \%$ of the variance of students' responsibilitytaking is explained by identity crisis.

Table 5 shows the variance analysis to verify the linearity of the relationship. The model is statistically significant at the level of $p<0.01$. Thus, we can use the regression model for this data.

Table 6 indicates the effect of identity crisis on responsibility-taking of onechild female students. In order to evaluate the impact of identity crisis on students' responsibility-taking, regression testing was used. Results of the above table show that the influence of identity crisis on students' responsibility-taking is statistically reverse and significant at the level of $\mathrm{p}<0.01$. In other words, identity crisis can predict responsibility-taking in students. That is, by decreasing identity crisis,

Table 4. Multiple correlation coefficient and coefficient of determination.

\begin{tabular}{ccccc}
\hline Model & Multiple correlation coefficient & Coefficient of determination & Adjusted coefficient of determination & Estimated standard error \\
\hline 1 & 0.385 & 0.148 & 0.142 & 4.354 \\
\hline
\end{tabular}

Table 5. Variance analysis to verify the linearity of ANOVA relationship.

\begin{tabular}{|c|c|c|c|c|c|c|}
\hline & Model & Total squares & Degrees of freedom (df) & Mean square & Relative value (F) & Significance level (p) \\
\hline \multirow{3}{*}{1} & Regression & 487.917 & 1 & 487.917 & & \\
\hline & Remaining & 2805.843 & 148 & 18.958 & 25.736 & $0.001\left(^{* *}\right)$ \\
\hline & Total & 3293.760 & 149 & $-\cdots$ & & \\
\hline
\end{tabular}

${ }^{* *}$ Significance at the level of 0.01 .

Table 6. The impact of identity crisis on students' responsibility-taking.

\begin{tabular}{ccccc}
\hline Step & Variables entered & B factor & Beta coefficient & T value \\
\hline \multirow{2}{*}{1} & Constant value & 25.446 & --- & 42.030 \\
& identity crisis & -0.374 & -0.385 & -5.073 \\
\hline
\end{tabular}

$\left.{ }^{*}\right)$ Significance at the level of $0.05 ;\left({ }^{*}\right)$ Significance at the level of 0.01 . 
their responsibility-taking increases. So, the secondary research hypothesis (HA) stating that identity crisis is a predictor of students' responsibility-taking is confirmed.

\section{Discussion and Conclusions}

In the present study, the relationship between responsibility-taking and identity crisis in one-child female high school students was investigated. The obtained results demonstrated that there is a significant reverse relationship between responsibility-taking and identity crisis components (drawback in long-term goals, indecision in selecting the job, lack of a suitable model for friendship, failure to comply with group commitment, having a negative view of oneself, lack of the spirit of effort and innovation, disruption in timing and total score of identity crisis) of students. That is, with reducing the aforesaid components, the rate of their responsibility-taking increases. The results achieved in this research are consistent with the findings obtained by Ramezani Disfani (2001), Sa'adati Shamir (2004) and Long and Chen (2009). In his study, Ramezani examined the effectiveness of educating responsibility-taking based on Glasser method on identity crisis of high school students in Isfahan and concluded that education of responsibility-taking has been effective in reducing adolescents' identity crisis.

Further, in the study by Long and Chen, issues such as communication with others and responsibility-taking were identified as the main dynamics in defining identity for female students.

The results obtained by Sa'adati Shamir revealed that there is a positive relationship between informational and normative identity styles with responsibilitytaking but a negative relationship between confused identity style and responsibility-taking.

Hence, according to the results of this research and also mentioned studies, it can be said that by accepting responsibility and succeeding in its implementation, a person can reinforce a sense of empowerment and self-confidence within himself and ultimately feel happy because he can effectively satisfy his basic needs. Additionally, he can believe that the control of his life affairs is in his own hands and he is able to provide better conditions for himself and in this way, he can take a big step in the formation of appropriate individual identity.

With a little reflection, it can be found that the main cause of neglecting the pains and disorders is not lack of public supervision and existence of dangerous intellectual supports; but it results from irresponsibility and escaping or shrinking from responsibilities. So today, we may see people who evade responsibility in order to release themselves from mental conflicts and boring efforts and activities (Gynat, 1999).

Another interesting result achieved by the investigation of the results obtained from the responsibility scale in this study (California Psychological Inventory) is that the rate of responsibility-taking among one-child students is slightly above average.

Considering that responsibility-taking is a skill and should be acquired like 
any other skill, naturally it is created gradually and from the beginning of life, meaning that a person can never show responsible behavior unless he has acquired it during his life (Nabavi, 1999) and sufficient time for this training of children by the parents is more in one-child families.

In fact, being responsible is a message that a one-child individual implicitly receives and considers as the characteristic of maturity. A sense of responsibility is usually more obvious in one-child individuals since they do not have relationship with anyone at home except the parents and for this reason, they learn many responsible behaviors from their parents.

Another result obtained from the present study is that in addition to responsibilitytaking, numerous other factors also have a role in identity formation of students and identity formation is not an independent event and depends on other internal and external factors.

Indeed, it can be concluded that the present research, in the evolution of investigating the factors affecting the identity, is consistent with the studies conducted by Karami (1996), Dehshiri (2005), Najafi, Ahadi and Delavar (2006), Daneshvar (1996), Raeisi (1997) and Ahmadi and Rezvaninezhad (1996) because in their studies, they have examined the impact of factors such as religiosity, self-esteem, education and group counseling, economic class and also family efficiency on creating identity crisis in people and in this research, responsibility-taking was investigated as another variable.

Besides, in the present study, identity crisis was tested as a predictor of students' responsibility-taking and the results showed that totally $15 \%$ of the variance of students' responsibility-taking is explained by identity crisis and thus, other factors can also have a role in students' responsibility-taking and in the introduction of the article, some of the factors affecting responsibility-taking which have been so far studied were reviewed.

However, according to the results of this research, identity plays an important role in predicting the students' responsibility-taking and since responsibility-taking is one aspect of identity development in adolescents, identity crisis can cause a reduction in responsibility-taking of students because the teenager still has not solved his problem with his identity and thus escapes from taking responsibility.

Marsia states that adolescents with confused identity have low self-esteem and assume responsibility for their own lives with difficulty. Additionally, these individuals have underdeveloped moral reasoning (Adelson, 1980).

The adolescent's inability to make an independent identity makes him faced with identity crisis and hence, he experiences confusion and shrinks from accepting the responsibilities assigned to him. This confusion in roles appears in the form of various behavioral disorders such as aggression, violence and running away from home and school.

\section{Limitations and Suggestions for Future Studies}

The statistical population of this study only includes the female students; but, 
future studies can study male and female students and compare the results of their studies with the results of the current study.

Moreover, future studies, can consider the effect of other factors on the relationship between responsibility-taking and identity crisis, to expand the results of this study.

\section{References}

[1] Ahadi, H. and Jamhari, F. (2001) Growth Psychology. Pardis, Tehran.

[2] Pick Hart, K. (2003) Educational Keys for Parents with One Child. 8th Edition, Saberin Publications, Iran.

[3] Cheshmeh, A. (2010) Gender Analysis of Adolescents' Responsibility-Taking and Its Relationship with socialization Practices in Family (District 15 of Tehran). Master's Thesis, University of Alzahra, Tehran.

[4] Khorramdel, S. (2008) Investigating the Relationship between Self-Esteem, Autonomy and Justice with Responsibility-Taking of Female Students in Varamin Middle Schools. Master's Thesis. University of Alzahra, Tehran.

[5] Daneshvar, A. (1996) Identity and Factors Affecting It in Students of Shiraz. Master's Thesis. Azad University, Khorasgan Branch, Isfahan.

[6] Raf atian, A. (2006) Responsibility-Taking. Qatreh Publication, Tehran.

[7] Ramezani Disfani, A. (2001) Effectiveness of Responsibility-Taking Based on Glasser Method on Identity Crisis of High School Students in Isfahan. Master's Thesis, University of Isfahan, Isfahan.

[8] Ahmadi, A. and Rezvani, M. (1996) The Impact of Group Training by Reality Therapy Method on Identity Crisis of Students at Shiraz University. Master's Thesis, Islamic Azad University of Shiraz, Shiraz.

[9] Esmaeili, J. (1997) Comparing Identity Crisis in Gifted and Normal Students of Second Grade of Middle School and First Year of High School in Tehran. Master's Thesis, Tarbiat Moallem University, Tehran.

[10] Raeisi, F. (1997) Examining the Effect of Group Counseling on Reducing the Identity Crisis of High School Girl Students in District 3 and 4 of Isfahan. Master's Thesis, Tarbiat Moallem University in Tehran, Tehran.

[11] Khoddami, F. (2012) Effectiveness of Problem-Solving Training to Mothers and Their Adolescent Girls in Improving the Relationship between Them. Master's Thesis, Ferdowsi University of Mashhad, Mashhad.

[12] Dehshiri, Gh. (2005) Investigating the Relationship between Religiosity and Identity Crisis among High School Students in Yazd. Journal of Education, 21, 78-98.

[13] Dehestani, M. (2008) Life Skills. Jeyhoun, Tehran.

[14] Sa'adati Shamir, A. (2004) Assessing the Relationship between Psychometric Identity Styles (Informational, Normative, Confused/Avoidant) with General Health and Responsibility-Taking of Students in Tehran Universities. Master's Thesis, Tarbiat Moallem University in Tehran, Tehran.

[15] Alavi Yazdi, M. (2003) Role Conflict and Values at Home and School and Their Influence on the Formation of Anti-Social Identities in Iranian Adolescents. Journal of Educational Sciences and Psychology, 4, 571-586.

[16] Mikaeili Mani', F. (2010) The Relationship between Identity Styles, Identity Commitment and Gender with Compatibility of Students. Psychological Studies of the Faculty of Educational Sciences and Psychology, 2, 51-68. 
[17] Najafi, M., Ahadi, H. and Delavar, A. (2006) Studying the Relationship between Family Function and Religiosity with Identity Crisis. Shahed University, Tehran.

[18] Nabavi, S. (1999) Strategies for Fostering a Sense of Responsibility-Taking in Adolescents. Master's Thesis, Educational Psychology, Tarbiat Modarres University, Tehran.

[19] Qasemi, T. (2002) Investigating the Mental Health Status of High School Girl Students in District 19 of Tehran. Monthly Pedagogical-Educational Magazine of Peyvand, No. 278.

[20] Karami, A. (1996) Examining Self-Esteem and Its Relationship with the Identity of Adolescents in Tehran. Master's Thesis, Tarbiat Moallem University, Tehran.

[21] Gynat, H. (1999) The Relationship between Parents and Children. Translated by S. Sartipi, Information Institute Publication, Tehran.

[22] Moradi, S. (2013) Comparing Behavioral Problems in Children of One-Child and Multi-Child Families with Regard to Demographic Factors of Parents. Master's Thesis, Faculty of Educational Sciences and Psychology, Shiraz University, Shiraz. 